\title{
Pengembangan Media Pembelajaran dengan Pendekatan Saintifik pada Materi Teorema Pythagoras
}

\author{
Nita Fatma Fauziah1, Fahrur Rozi Hadiyanto ${ }^{2 *}$ \\ ${ }^{1}$ Universitas Pawyatan Daha, Kediri \\ ${ }^{2}$ Universitas Islam Kadiri, Kediri \\ *email: fahrurrozi242604@gmail.com
}

\begin{abstract}
The Pythagorean Theorem is an important material to study because the application of this material is used to study other material in mathematics as well as in other subjects. The success of students in learning the Pythagorean theorem material can be influenced by several factors, one of which is the way the teacher teaches the material. A valid and practical learning media is one way of teaching the Pythagorean theorem so that it is better understood by students. The purpose of this research is to produce a valid and practical Pythagorean theorem learning media. The learning media (students work sheet) development model refers to the Plomp development model which consists of: (1) the initial investigation stage, (2) the design stage, (3) the realization stage, and (4) the test, evaluation, and revision stages. Based on the analysis of development data, it is found that the learning media developed are valid and practical.
\end{abstract}

Keywords: The Pythagorean Theorem; The Learning Media; Student Work Sheet

\begin{abstract}
Abstrak
Theorema Pytagoras adalah materi yang penting untuk dipelajari karena aplikasi maetri ini digunakan untuk mempelajari materi lain dalam matematika dan pelajaran lain. Keberhasilan dalam memepelajari materi teorema Pythagoras salah satunya dapat dipengaruhi oleh cara guru dalam membelajarkan materi ini. Media pembelajaran yang valid dan praktis adalah salah satu cara membelajarkan materi teorema Pythagoras agar lebih dipahami oleh siswa. Tujuan dalam penelitian ini adalah untuk menghasilkan media pembelajaran teorema Pythagoras yang valid, dan praktis. Model pengembangan media pembelajaran mengacu pada model pengembangan Plomp yang terdiri atas: (1) tahap investigasi awal, (2) tahap desain, (3) tahap realisasi, dan (4) tahap tes, evaluasi, dan revisi. Berdasarkan analisis data pengembangan diperoleh hasil bahwa media pembelajaran yang dikembangkan dinyatakan valid, dan praktis.
\end{abstract}

Kata Kunci: Teorema Pythagoras; Media Pembelajaran; Lembar Kegiatan Siswa

\section{PENDAHULUAN}

Matematika sebagai ilmu dasar memiiliki peran pentiing dalam pengembangan Ilmu Pengetahuan dan Teknologi (IPTEK). Hal ini yang menyebabkan matematika dicantumkan pada kurikulum di semua jenjang sekolah yaitu mulai dasar sampai Menengah Atas (Permendikbud, 2014). Matematika juga ilmu dengan susunan yang hirarki, logis, dan sistematis mulai dari konsep sederhana hingga kompleks (Ramdani, Yani 2006). Oleh karenanya, dalam matematika keberhasilan siswa mempelajari suatu materi akan berpengaruh terhadap keberhasilan dalam mempelajari materi selanjutnya. 
Teorema Pythagoras adalah materi yang dipelajari siswa di kelas VIII. Materi ini penting untuk dipelajari karena aplikasi materi ini digunakan untuk mempelajari materi lain dalam matematika dan pelajaran lainnya (Kemendikbud, 2013). Namun pada kenyataannya siswa masih kesulitan dalam mempelajari materi ini. Sebagian besar dari siswa hanya menghafal bila teorema Pythagoras adalah " $a^{2}+b^{2}=c^{2}$ ". Hal ini menyebabkan kesulitan jika teorema ini disajikan dalam bentuk soal cerita yang membutuhkan penalaran lebih (Maulida dkk, 2019; Rohmah, 2020). Selain itu juga ditemukan siswa yang hanya langsung mengalikan nilai yang ada dalam soal cerita tanpa menggunakan konsep teorema Pythagoras. Kesulitan lain yang juga banyak ditemukan dalam soal cerita materi teorema Pythagoras diantaranya kesuitan menentukan apa yang diketahui dan ditanyakanserta menuliskan rumus teorema Pythagoras yang akan digunakan. Selain itu tidak sedikit ditemukan kekeliruan perhitungan dalam menentukan akar dan kuadrat. Kesulitan-kesulitan ini menunjukkan kurangnya pemahaman konsep teorema Pythagoras (Irnayanti dkk., 2019).

Keberhasilan dalam mempelajari materi teorema pytagoras salah satunya dapat dipengaruhi oleh cara guru dalam membelajarkan materi ini. Banyak pembelajaran yang dilakukan saat ini masih terpusat pada guru, ini menyebabkan siswa cenderung pasif dan tidak tertarik terhadap matematika(Adriani \& Harianto, 2010; Neumann, 2014). Oleh karenanya, diperlukan usaha lebih yang harus dilakukan oleh guru untuk menarik perhatian siswa untuk mempelajari matematika. Hal ini dapat dilakukan dengan melibatkan siswa untuk memahami sendiri bagaimana teorema ini temukan serta mengetahui pemanfaatanya dan aplikasinya dalam kehidupan nyata.

Pada Kurikulum 2013, pendekatan saintifik dianggap sebagai pendekatan yang efektif diterapkan dalam pembelajaran. Hal ini dikarenakan pendekatan saintifik dapat mencakup tiga ranah, yaitu ranah sikap, ranah keterampilan, dan ranah pengetahuan. Menurut Mendiknas (2013) untuk membantu menumbuhkan kreativitas siswa dalam proses pembelajaran matematika terdapat lima proses sesuai dengan pendekatan saintifik yaitu, mengamati, menanya, mengumpulkan informasi, mengolah informasi, dan mengkomunikasikan.

Berdasarkan uraian di atas, diperlukan pengembangan media pembelajaran pada materi teorema Pythagoras untuk menarik minat siswa. Hal tersebut sesuai dengan pernyataan Subanji (2014) bahwa untuk mewujudkan pembelajaran bermakna guru senantiasa mengembangkan pembelajaran inovatif, lembar kegiatan siswa yang menantang serta media pembelajaran yang kreatif. Media pembelajaran bisa diartikan sebagai segala sesuatu yang dapat digunakan/dipakai untuk menyampaikan materi pembelajaran sehingga dapat tercipta lingkungan belajar yang kondusif untuk siswa, sehinga dapat dilakukan proses belajar yang efisien dan efektif (Munadi, 2013). Tujuan 
utama dari pembelajaran adalah penekanan pada pemahaman konsep, jadi siswa dibimbing untuk menemukan sendiri terkait konsep teorema Pythagoras. Oleh karena itu penggunaan pendekatan saintifik sangat tepat digunakan dalam pengembangan perangkat untuk membelajarkan materi teorema Pythagoras

\section{METODE}

Pengembangan media pembelajaran ini termasuk dalam penelitian pengembangan dan mengacu pada model pengembangan plomp. Menurut Hobri (2010) model pengembangan plomp ini terdiri dari 5 langkah/tahap yaitu 1) investigasi awal, 2) desain, 3) realisasi, 4) evaluasi, tes, dan revisi, dan 5) implementasi. Namun, pada pengembangan ini hanya dilakukan sampai pada tahap evaluasi, tes, dan revisi dikarenakan ketersediaan waktu pelaksanaan.

Pada penelitian pengembangan ini akan dilakukan 2 uji untuk mengetahui kualitas dari produk, yaitu uji kevakidan dan uji kepraktisan. Uji kevalidan dilakukan untuk menguji kesesuaian pengembangan produk dengan teori pengembangan. Sedangkan uji kepraktisan dilakukan untuk menguji/mengetahui keterterapan media pembelajaran yang dihasilkan dalam proses pembelajaran, hal ini meliputi apakah media mudah dan menyenangkan untuk digunakan dalam pembelajaran

Uji kevalidan dilakukan menggunakan lembar validasi untuk perangkat pembelajaran. Lembar validasi diisi oleh 2 orang dosen matematika yang berpengalaman di bidangnya. Uji kepraktisan dilakukan dengan menggunakan angket respon mahasiswa terhadap media pembelajaran. Angket respon siswa diisi oleh 10 orang mahasiswa program studi matematika sebagai subjek uji coba.

Teknik analisis data untuk uji kevalidan dan kepraktisan yang dilakukan meliputi, 1) merekapitulasi data hasil penilaian produk dalam bentuk tabel yang meliputi aspek, indikator, dan nilai untuk masing- masing validator, 2) menentukan rata-rata dari nilai hasil penilaian dari semua validator untuk masing-masing indikator, dan 3) menentukan skor vkevalidan atau skor kepraktisan, yaitu berupa nilai rata-rata total dari rata-rata nilai untuk semua indikator (Hobri, 2010). Langkah selanjutntya, hasil analisis data untuk uji kevalidan dan kepraktisan akan dibandingkan dengan kriteria kevalidan dan kepraktisan seperti yang ada pada Tabel 1 (Hobri, 2010).

Tabel 1. Kriteria Kevalidan atau Kepraktisan Media pembelajaran

\begin{tabular}{ccc}
\hline Skor & Kategori & Keterangan \\
\hline $3,75 \leq V a \leq 4$ & Sangat valid/ sangat praktis & Tidak revisi \\
$3 \leq V a<3,75$ & Valid/ praktis & Tidak revisi \\
$2,5 \leq V a<3$ & Cukup valid/ cukup praktiss & Revisi sebagian \\
$1,75 \leq V a<2,5$ & Kurang valid/ kurang praktis & Revisi sebagian \\
$1 \leq V a<1,75$ & Tidak valid/ tidak praktis & Revisi total \\
\hline
\end{tabular}




\section{HASIL DAN PEMBAHASAN}

Hasil pengembangan ini adalah berupa media pembelajaran materi teorema Pythagorasyang yaitu Lembar Kegiatan Siswa (LKS) digunakan untuk satu kali pertemuan. Pada kegiatan mengamati siswa diberikan contoh sebuah permasalahan yang disertai gambar berupa ilustrasi. Pada kegiatan menyanya siswa diminta untuk menuliskan pertanyaan terkait permasalahan pada kegiatan mengamati. Selanjutnya kegiatan mengumpulkan dan mengolah informasi siswa diberikan media manipulatif berupa potongan-potongan persegi dalam amplop dengan berbagai ukuran yang nantinya dapat ditempelkan pada LKS.

Berikut data yang diperoleh dari uji kevalidan yang terdiri dari data hasil uji kevalidan media pembelajaran teorema Pythagoras. Analisis data hasil uji kevalidan media pembelajaran teorema Pythagoras dari validator di sajikan pada Tabel 2 berikut.

Tabel 2. Analisis Data Hasil Uji Kevalidan RPP oleh Validator

\begin{tabular}{clccc}
\hline No. & \multicolumn{1}{c}{ Aspek yang Dinilai } & $\begin{array}{c}\text { Skor } \\
\text { Kevalidan }\end{array}$ & $\begin{array}{c}\text { Kriteria } \\
\text { Kevalidan }\end{array}$ & Keterangan \\
\hline Materi & 3 & Valid & Tidak Revisi \\
\hline $1 . \quad \begin{array}{l}\text { Media yang digunakan sesuai } \\
\text { dengan materi pelajaran. }\end{array}$ & 3 & Valid & Tidak Revisi \\
2. & $\begin{array}{l}\text { Media yang digunakan sesuai } \\
\text { dengan tujuan pembelajaran. } \\
\text { Kejelasan petunjuk penggunaan }\end{array}$ & 3 & Cukup valid & $\begin{array}{c}\text { Revisi } \\
\text { sebagian }\end{array}$ \\
\hline Kualitas Media & 3,5 & Valid & Tidak Revisi \\
\hline $4 . \quad \begin{array}{l}\text { Penampilan media menarik } \\
\text { Kemudahan dalam penggunaan } \\
\text { media }\end{array}$ & 3 & Valid & Tidak Revisi \\
\hline Daya Tarik & $\begin{array}{l}\text { Penggunaan media dapat } \\
\text { mengurangi ketergantungan siswa } \\
\text { pada guru. }\end{array}$ & 3 & Valid & Tidak Revisi \\
\hline $\begin{array}{l}\text { Penggunaan media dapat } \\
\text { meminimalisir salah persepsi yang } \\
\text { terjadi pada siswa. }\end{array}$ & 3 & Valid & Tidak Revisi \\
$8 \quad \begin{array}{l}\text { Pengounaan media dapat } \\
\text { memotivasi siswa dalam memahami } \\
\text { materi. }\end{array}$ & 3 & Valid & Tidak Revisi \\
\hline
\end{tabular}

Berdasarkan paparan di atas, maka secara umum diperoleh skor kevalidan media pembelajaran teorema Pythagoras adalah 3,06, sehingga media pembelajaran yang dikembangkan dinyatakan memenuhi kriteria yaitu valid dan tidak memerlukan revisi. Namun demikian, revisi akan tetap dilakukan demi kesempurnaan produk. Revisi 


\section{Mandalika Mathematics and Education Journal}

Volume 3 Nomor 1, Juni 2021

e-ISSN 2715-1190| | p-ISSN 2715-8292

DOI: http://dx.doi.org/10.29303/jm.v3i1.2591

yang dilakukan oleh pengembang berdasarkan saran dan komentar dari validator untuk menyempurnakan media pembelajaran teorema Pythagoras yang dikembangkan.

Berikut ini adalah beberapa hal yang perlu direvisi media pembelajaran teorema Pythagoras yang dikembangkan. Pada gambar 1 dibawah ini terdapat cuplikan dari kegiatan mengamati pada LKS.

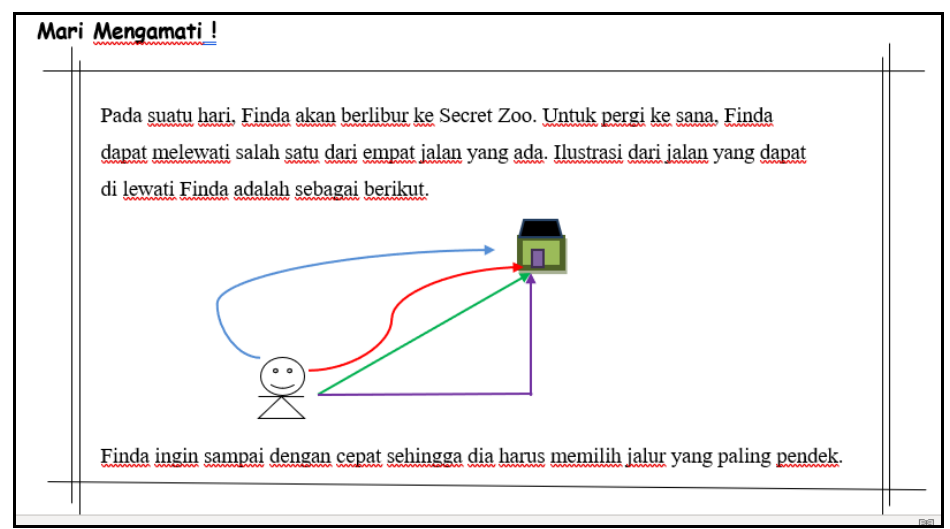

Gambar 1. Kegiatan Mengamati pada LKS

Berdasarkan saran dari validator, untuk kegiatan mengamati ilustrasi akan lebih menarik lagi jika disajikan dalam bentuk video. Tujuan dari kegiatan mengamati dengan memperlihatkan video ini adalah agar siswa lebih tertarik dan bersemangat dalam pembelajaran. Paseleng \& Arfiyani (2015) serta Putri \& Dewi (2020)yang mengatakan bahwa media pembelajaran berupa video bisa membuat siswa tertarik. Berdasarkan saran dari validator, pegembang melakukan revisi untuk kegiatan mengamati. Pada awalnya pengembang ingin memakai video dari sumber lain, tetapi karena pengembang tidak menemukan video yang berisi tentang permasalah yang sesuai akhirnya pengembang memutuskan untuk membuat sendiri video tersebut dengan proses pengambilan gambar yang diperankan oleh pengembang sendiri. Hasil revisi seperti yang ditujukkan pada Gambar 2.

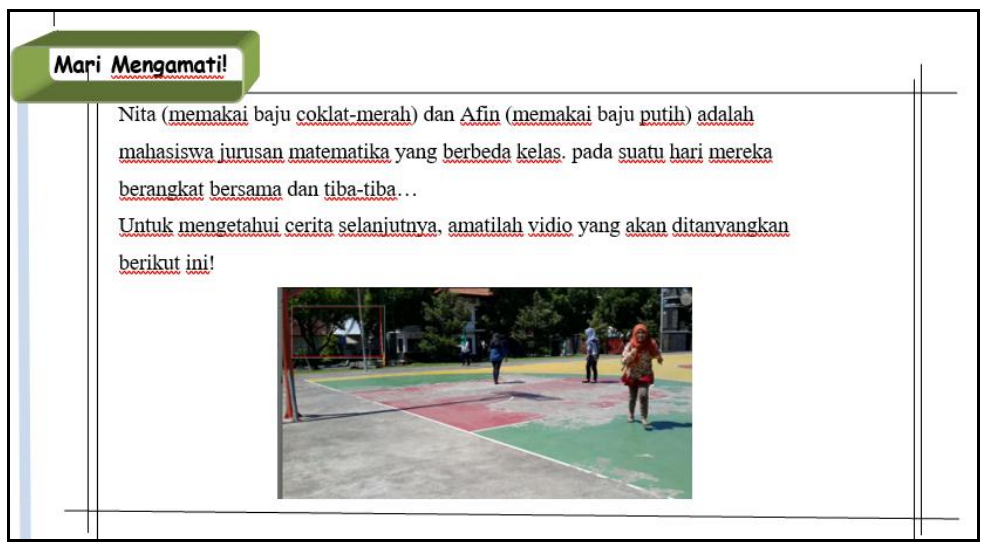

Gambar 2. Hasil Revisi Kegiatan Mengamati pada LKS 


\section{Mandalika Mathematics and Education Journal}

Volume 3 Nomor 1, Juni 2021

e-ISSN 2715-1190| | p-ISSN 2715-8292

DOI: http://dx.doi.org/10.29303/jm.v3i1.2591

Revisi lain untuk penyempunaan media pembelajaran teorema pytagoras adalah saran dari validator pada kegiatan mengumpulkan informasi untuk mengubah instruksi dari yang hanya menyatukan menjadi menempelkan persegi-persegi seperti contoh yang ditunjukkan pengembang pada LKS. Aktifitas siswa yang meningkat selama pembelajaran dapat membuat siswa lebih tertarik dalam belajar dan akan berpengaruh pada peningkatkan prestasi/hasil belajar siswa (Wahjudi, 2015). Hal ini seperti yang ditunjukkan pada Gambar 3 dan 4.

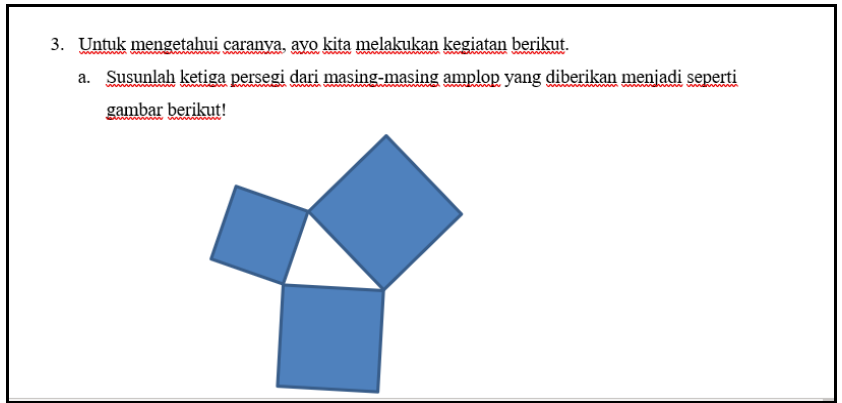

Gambar 3. Cuplikan 1 Kegiatan Mengumpulkan Informasi

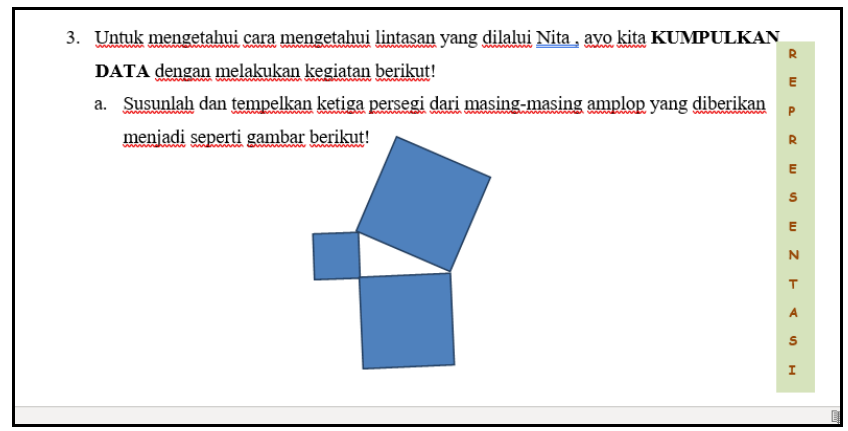

Gambar 4. Hasil Revisi Cuplikan 1 Kegiatan Mengumpulkan Informasi

Perubahan instruksi pada langkah sebelumnya juga berpengaruh pada langkah berikutnya yaitu menyediakan tempat untuk menempel persegi-persegi dalam amplop langsung pada LKS ditunjukkan pada gambar 5. Tujuan dari kegiatan ini agar siswa lebih dengan mudah untuk mengerjakan tahap selanjutnya dan tidak perlu mencari tempat lain menyatukan persegi-persegi tersebut. 


\section{Mandalika Mathematics and Education Journal}

Volume 3 Nomor 1, Juni 2021

e-ISSN 2715-1190| | p-ISSN 2715-8292

DOI: http://dx.doi.org/10.29303/jm.v3i1.2591

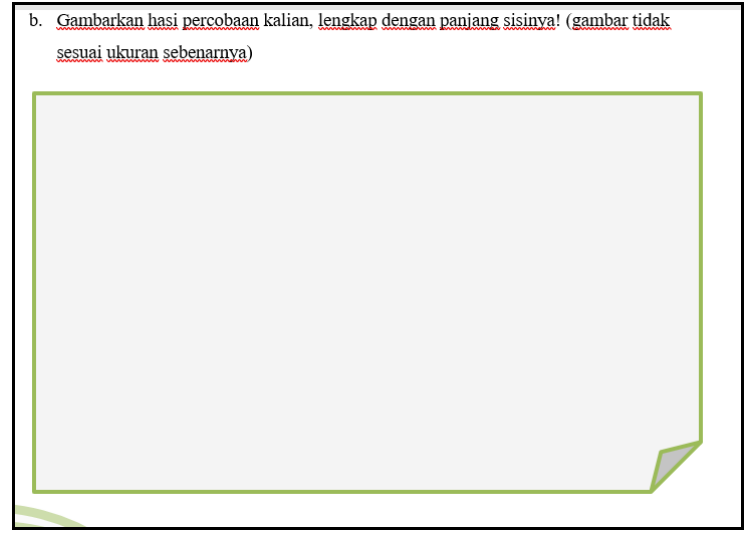

Gambar 5. Cuplikan 2 Kegiatan Mengumpulkan Informasi

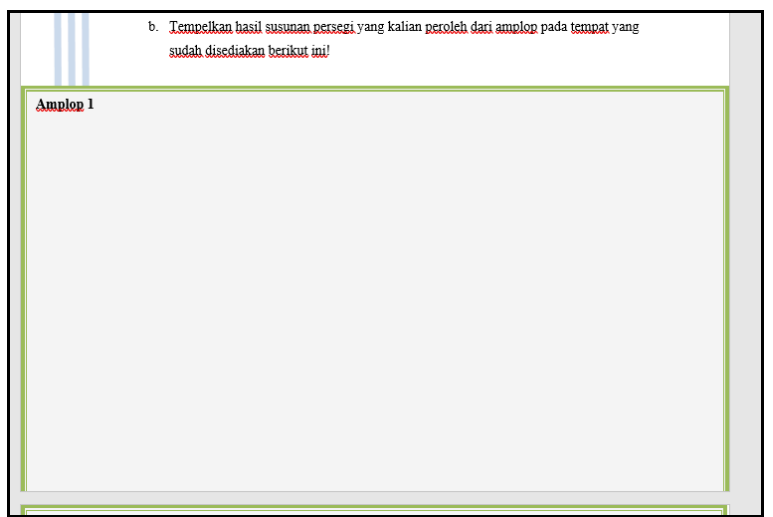

Gambar 6. Hasil Revisi Cuplikan 2 Kegiatan Mengumpulkan Informasi

Tabel 3. Analisis Data Hasil Uji Kepraktisan LKS oleh Siswa Subjek Uji Coba

\begin{tabular}{clccc}
\hline No & \multicolumn{1}{c}{ Aspek yang Dinilai } & $\begin{array}{c}\text { Skor } \\
\text { Kepraktisa } \\
\mathbf{n}\end{array}$ & $\begin{array}{c}\text { Kriteria } \\
\text { Kepraktis } \\
\text { an }\end{array}$ & $\begin{array}{c}\text { Keteranga } \\
\mathbf{n}\end{array}$ \\
\hline $1 . \quad \begin{array}{l}\text { Guru menggunakan media yang } \\
\text { menarik }\end{array}$ & 3,50 & Praktis & Tidak Revisi \\
2. $\quad \begin{array}{l}\text { Media yang dipakai dalam } \\
\text { pembelajaran ini bermanfaat bagi }\end{array}$ & 3,3 & Praktis & Tidak Revisi \\
saya. & $\begin{array}{l}\text { Dengan Menggunakan media } \\
\text { pembelajaran ini membuat saya lebih } \\
\text { memahami materi pembelajaran. }\end{array}$ & 3,7 & $\begin{array}{c}\text { Cukup } \\
\text { Praktis }\end{array}$ & Tidak Revisi \\
Media yang digunakan membuat saya \\
$\begin{array}{l}\text { lebih bersemangat/ tidak bosan dalam } \\
\text { belajar. }\end{array}$ & 3,4 & Praktis & Tidak Revisi \\
\hline
\end{tabular}

Data uji kepraktisan media pembelajaran teorema Pythagoras diperoleh melalui hasil pengisian angket respon siswa terhadap perangkat yang dikembangkan. Secara 


\section{Mandalika Mathematics and Education Journal}

Volume 3 Nomor 1, Juni 2021

e-ISSN 2715-1190| | p-ISSN 2715-8292

DOI: http://dx.doi.org/10.29303/jm.v3i1.2591

keseluruhan, skor kepraktisan media pembelajaran teorema Pythagoras yang dikembangkan adalah 3,48. Skor ini menunjukkan bahwa media pembelajaran teorema Pythagoras yang dikembangkan sudah praktis sehingga tidak memerlukan revisi. Namun demikian, pengembang tetap merevisinnya berdasarkan saran dan komentar dari subjek uji coba demi kesempurnaan media pembelajaran teorema Pythagorasyang dikembangkan.

Saran dari subjek uji coba adalah pada langkah mengumpulkan informasi mengenai pengisian kolom panjang sisi-sisi segitiga yang terbentuk. Langkah tersebut tidak relevan dengan apa yang diminta/dinstruksikan yang hanya mengintruksikan untuk menuliskan besar sudut. Hal ini seperti yang ditujukkan pada Gambar 7 tentang cuplikan 3 kegiatan mengumpulkan informasi.

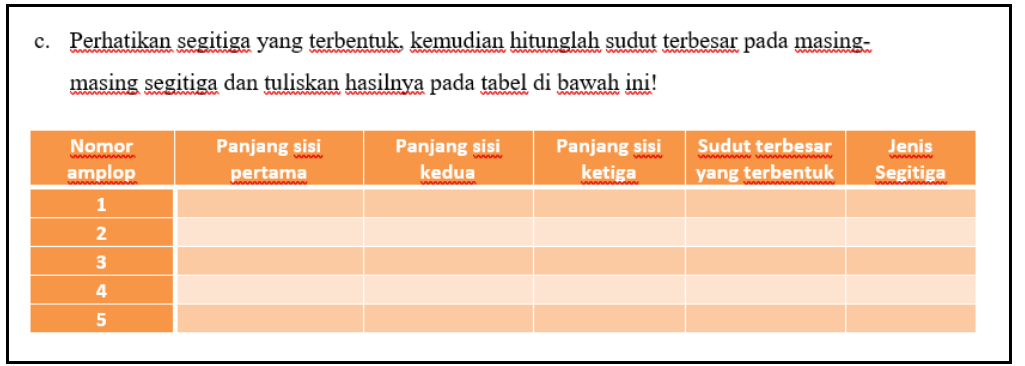

Gambar 7. Cuplikan 3 Kegiatan Mengumpulkan Informasi

Berdasarkan saran dari subjek uji coba, pengembang menghilangkan isian pada kolom yang tidak perlu pada langkah mengumpulkan informasi. Hal ini seperti yang ditunjukkan pada gambar 8 mengenai hasil revisi pada kegiatan mengumpulkan informasi.

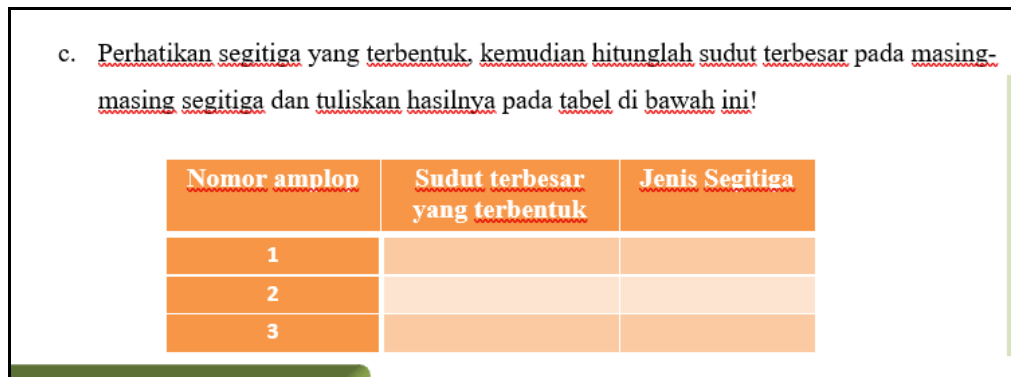

Gambar 8. Hasil Revisi Cuplikan 3 Kegiatan Mengumpulkan Informasi

\section{PENUTUP}

Pengembangan media pembelajaran teorema Pythagoras yang terdiri dari yang terdiri dari RPP, LKS dan Lembar Penilaian yang digunakan untuk satu kali pertemuan ini menggunakan uji kevalidan, dan uji kepraktisan sebagai tolak ukur untuk mengetahui 
kualitas produk yang dikembangkan. Pada analisis data yang dilakukan untuk menguji kevalidan oleh validator, media pembelajaran teorema Pythagoras dinyatakan valid dengan skor kevalidan 3,06. Karena memperoleh nilai kevalidan 3,06 maka media pembelajaran teorema Pythagoras tidak memerlukan revisi, namun pengembang tetap melakukan revisi demi kesempurnaan produk, dimana bagian yang direvisi ada pada penetapan aturan permainan. Sedangkan untuk uji kepraktisan media pembelajaran teorema Pythagoras yang dilakukan melalui lembar respon subjek uji coba, diperoleh hasil bahwa media pembelajaran teorema Pythagoras yang dikembangkan mendapatkan skor kepraktisan 3,48 sehingga dapat dinyatakan valid dan tidak perlu direvisi. Namun demikian pengembang tetap merevisi demi kesempurnaan media pembelajaran.

Berdasarkan uraian di atas, beberapa saran pemanfaatan dan pengembangan berkaitan dengan pengembangan media pembelajaran teorema Pythagoras adalah sebagai berikut:

1. Hasil pengembangan berupa mediapembelajaran teorema Pythagoras ini diharapkan dapat digunakan/dipakai sebagai alternatif guru dalam pembelajaran untuk siswa SMP kelas VIII.

2. Bagi pengembang lain yang berminat atau tertarik dalam pemrograman, pengembangan produk dengan materi serupa dapat dikembangkan menjadi PBK (Pembelajaran Berbantuan Komputer).

\section{REFERENSI}

Adriani, N., \& Harianto. (2010). Pembelajaran Multimedia di Sekolah. Jakarta: Prestasi Pustaka.

Hobri. (2010). Metodologi Penelitian Pengembangan. Jember: Pena Salsabila.

Irnayanti, A., Karniman, T. S., \& Anggraini. (2019). Penerapan Model Pembelajaran Penemuan Terbimbing dan Metode Drill untuk Meningkatkan Hasil Belajar Siswa pada Materi Teorema Phythagoras di Kelas VIII C SMP Negeri 3 Balinggi. Jurnal Elektronik Pendidikan Matematika, 6(4), 418-429.

Maulida, R. F., Darmawan, P., \& Prayekti, N. (2019). Analisis Pemahaman Siswa dalam Menyelesaikan Soal Cerita Terkait Teorema Pythagoras. Prosiding Seminar Nasional MIPA UNIBA 2019, 198-204.

Munadi, Y. (2013). Media Pembelajaran (Sebuah Pendekatan Baru). Jakarta: Referensi.

Neumann, M. D. (2014). Mathematics Teaching: Interpreting and Responding to Children's Thinking. Investigations in Mathematics Learning, 6(3), 1-28.

Paseleng, M. C., \& Arfiyani, R. (2015). Pengimplementasian Media Pembelajaran Berbasis Multimedia Interaktif pada Mata Pelajaran Matematika di Sekolah Dasar. Scholaria, 5(2), 131-149.

Putri, L. A., \& Dewi, P. S. (2020). Media Pembelajaran Menggunakan Video Atraktif pada Materi Garis Singgung Lingkaran. Mathema: Jurnal Pendidikan Matematika, 2(1), 32-39. 
https://doi.org/10.33365/jm.v2i1.568

Rohmah, A. S. (2020). Analisis Kesalahan Siswa MTs dalam Menyelesaikan Soal pada Materi Teorema Pythagoras. JPMI: Jurnal Pembelajaran Matematika Inovatif, 3(5), 433-442. https://doi.org/10.22460/jpmi.v3i5.433-442

Subanji, S. (2014). TEQIP sebagai Wahana Mewujudkan Pembelajaran Bermakna dan Membangun Karakter Bangsa. J-Teqip, 5(2), 307-318.

Wahjudi, E. (2015). Penerapan Discovery Learning Dalam Pembelajaran IPA sebagai Upaya untuk Meningkatkan Hasil Belajar Siswa Kelas IX-I di SMP Negeri 1 Kalianget. LENSA (Lentera Sains): Jurnal Pendidikan IPA, 5(1), 1-15. https://doi.org/10.24929/lensa.v5i1.242 